\title{
HET VERGAAN VAN DE ZEEMEEUW IN 1825
}

DOOR

H. M. HULSMAN O.P

De Curaçaosche courant van Zaterdag 5 Maart 1825 verscheen met een bericht, dat op Dinsdag tevoren Z.Ms. brik de Kemphaan, gecommandeerd door den Kapitein-luitenant van Rijn vertrokken was ,hebbende onder konvooi tot de Monapassaat, het Nederlandsche fregatschip de Zeemeeuw schipper J. R. Böning"'.

Hetzelfde blad meldde op Zaterdag 19 Maart, dat Woensdag de Kemphaan weer was teruggekeerd, maar van de Zeemeeuw werd verder niets vernomen. We kunnen ons indenken, dat dit verlies jarenlang aanleiding gegeven heeft tot allerlei vermoedens en veronderstellingen, vooral daar men hier de mening was toegedaan, welke Teenstra weergeeft in zijn in 1836 verschenen boekje, dat de Zeemeeuw het eerste goud van Aruba aan boord had.

De jaren echter hadden ook de herinnering aan dit scheepsdrama uitgewist, toen op 6 Januari 1908 in no. 45 van D e V r ijm o e dig e het volgend artikel verscheen:

\section{Een drama, afgespeeld op de Caraïbische zee.}

Een drama, lang geleden afgespeeld op de wateren der Caraibische zee en waarover tot nu toe een dikke sluier heeft gehangen gaf jarenlang aanleiding tot allerlei vermoedens en veronderstellingen, die, bij het lichten van dien sluier, niet juist blijken te zijn geweest.

$\mathrm{Na}$ lang wachten, ten einde ons gegeven woord gestand te doen, is het ons eindelijk vergund, dien sluier op te lichten en mededeelingen te doen, die veel kans geloopen hebben, voor altijd onbekend te zijn gebleven.

Het was den vierden Mei 1861. In eene der baaien van het schiereiland Guagira lag een sierlijk gebouwde, spierwit geschilderde schoener, metende ongeveer tachtig ton. Hij was slank en dobberde elegant op de zachte deining, die de Caraïbische zee

$$
-129-
$$


aan de noordkust van dat schiereiland veroorzaakt. Hij had twee kanonnen aan boord om, door het lossen van twee schoten, den bewoners van die kust kennis te geven, dat men handel met hen wilde drijven. Op het achterschip van den schoener zaten de kapitein en een oude zeeman, die het geweer van den kapitein schoonmaakte. Al pratende vroeg deze aan den ouden man, of het waar was hetgeen men van hem vertelde, nl. dat hij als kajuitsjongen aan boord van een zeeroover had gevaren. De oude man sloeg een wantrouwenden blik op den kapitein, doch werd weldra gerust gesteld met de mededeeling, dat hij als kajuitsjongen voor niets verantwoordelijk was, dat aan boord mocht hebben plaats gehad en zeker zelfs niet wist, met welk doel het schip waar hij aan boord was, weggezeild was.

$\mathrm{Na}$ veel praten en beloven ving de zeeman aldus aan. „Geef mij uw woord van eer als caballero, dat gij, zoolang ik leef, u geen woord zult laten ontvallen van hetgeen ik u ga mededeelen". Dit woord werd gegeven - en ook gehouden.

„Welnu, wij zeilden op een Zaterdagmorgen uit de haven van Curaçao met een topzeilschoener, Beluche genaamd, werkten op onder de kust en liepen des nachts tusschen Curaçao en Bonaire door, onzen koers noordwaarts richtende. Na verloop van drie dagen kregen wij Porto-Rico in het gezicht en bleven wij gedurende vijf dagen benoorden de Mona-passage op en neder houden. Den zesden dag werd des morgens omstreeks acht uur door den uitkijk in de mars den kapitein toegeroepen: „In het zuiden een brik in het gezicht". Onmiddellijk werd er koers gezet op de brik en, haar genaderd zijnde, een stopschot gelost. De brik zeilde door, doch een tweede schot joeg haar een kogel door het grootzeil en deed haar bijdraaien. Van boord den topzeilschoener werd daarop de boot te water gelaten. De kapitein en dertien man, allen zwaar gewapend, namen er plaats in en men roeide naar de brik toe. Aldaar aangekomen, stonden zij allen in een oogwenk op het dek van de brik, die De Zeemeeuw bleek te zijn, den 1sten Februari (moet zijn Maart) uit de haven van Curaçao naar Nederland vertrokken. Aan den kapitein van dit vaartuig werd bevolen al het goud dat hij aan boord had, onmiddellijk af te geven. Aan dat bevel geen gehoor willende geven, werd hij bedreigd opgehangen te zullen worden. Deze bedreiging deed hem besluiten het goud, dat hij op Curaçao ontvangen had en bestemd was, om naar Nederland te worden overgebracht, af te geven. Vergezeld van een der zeeroovers begaf hij zich in de kajuit en bracht weldra een kist op dek, die het bedoelde goud be- 
vatte. Een verder onderzoek, door den rooverkapitein zelf gedaan, deed hem nog verscheidene zaken van waarde vinden, die alle in de boot van de Beluche en later aan boord gebracht werden. Dit afgeloopen zijnde, werd den kapitein van De Zeemeeuw medegedeeld, dat zijn schip in den grond geboord zou worden, hij met het volk de brik moest verlaten en met zijne zeilboot naar St. Domingo of Porto Rico zeilen kon. De zeilboot werd in orde gebracht en van water en provisie voorzien. Alles gereed zijnde, begaf het scheepsvolk zich in de boot en wachtte op den kapitein, een bisschop en mevrouw D., welke twee laatsten passagiers waren, om in de boot te stappen. Een vreeselijke scène had toen plaats; de rooverkapitein weigerde, mevrouw D. met de boot van $D e$ Zeemeeuw te laten vertrekken, welke gelast werd, onmiddellijk weg te zeilen. MevrouwD. werd met geweld in de boot van de Beluche gedragen en aan boord gebracht, waar haar de kajuit van den kapitein als verblijfplaats werd aangewezen. Dit alles afgeloopen zijnde, werden de vier kanonnen van de Beluche geladen en werd er koers gezet op de boot van De Zeemeeuw, die ongeveer eene mijl ver weggezeild was. Op twee honderd pas van. de zeilboot genaderd, werden twee kanonnen op haar gericht en afgevuurd. Een der kogels sloeg een stuk van de voorsteven weg. en een oorverdoovend geroep van „Genade! genade!” steeg uit de boot op, doch tevergeefs. Een derde en vierde schot troffen de boot midscheeps en deed haar met man en muis in de diepte verdwijnen, De Zeemeeuw werd vervolgens in den grond geboord, en de koers van de Beluche zuidwaarts gesteld. Na drie dagen bereikte zij de westkust van het eiland Bonaire, waaronder drie dagen op- en onder gehouden werd.

Mevrouw D. weigerde, behalve een kopje sago-pap, eenig ander voedsel te gebruiken. $\mathrm{Na}$ aldus zes dagen aan boord van de $\mathrm{Be}$ luche te hebben doorgebracht, werd haar den zevenden dag, des morgens, door den Kapitein (B. L.) een kopje sago-pap gebracht, dat hij eigenhandig had klaar gemaakt; eenige uren later stierf Mevr. D. aan hevige maagkrampen. Het lijk werd in een stuk zeildoek genaaid, eenige steenen erbij gevoegd en in zee begraven. De kanonnen van de Beluche werden in het ruim nedergelaten en onder de ballaststeenen verscholen. Twee dagen later zeilde de Beluche doodkalm de haven van Curaçao binnen. Het geroofde werd des nachts van boord gehaald en op de werf van Sjoon N. M. gelost.

Aldus verging in de diepte der Caraïbische zee de Hollandsche 
brik De Zeemeeuw, die door het Hollandsche oorlogsschip De Valk (Kemphaan) tot in de nabijheid van de Mona-passage begeleid werd en over welker wedervaren tot nu toe nooit een helder licht heeft geschenen. De politie heeft toenmaals niets vermoed van hetgeen met De Zeemeeuw had plaats gehad, want zij die bij het gebeurde tegenwoordig waren, hebben als het graf gezwegen.

Vele jaren na het gebeurde met De Zeemeeuw vernam ik, dat op een bal het kruis, toebehoord hebbende aan den bisschop, die zich aan boord van de brik bevond, en de haarkam van mevrouw D. gedragen en herkend zijn geworden. Nu heb ik u alles medegedeeld wat ik mij herinneren kan. Herinner gij u nu steeds uwe belofte".

Indachtig aan de spreuk „Laat de dooden rusten” hebben wij zorgvuldig het noemen van namen vermeden en, getrouw aan onze belofte, eerst na den dood van den ouden zeeman besloten, zijn verhaal openbaar te maken, - een drama, dat drie en negentig (drie en tachtig) jaar geleden heeft plaats gehad in de nabijheid van Curaçao en hier niet bekend is.

J. H. B. G.

We hebben bovenstaand sensationeel verhaal voorzien van enkele verbeteringen tusschen ( ) in de tekst.

Ditzelfde verhaal over het vergaan van de Zeemeeuw heeft dezelfde schrijver J. H. B. Gravenhorst later nog eens beschreven, als onderdeel van een groot feuilleton in de A mig o e di $\mathrm{Cu}$ r a ç a o, dat begint in het nummer van 13 Juni 1914 en tot het laatste nummer van die jaargang doorloopt. Dit feuilleton heet: „Van Curaçao naar New Orleans langs een omweg”, en speelt voornamelijk onder de Indianen van Goagira. De kapitein van het schip, Gravenhorst zelf, heet daar Edgar en de hoofdpersoon is een Indiaanse prinses Humare, waarmede hij trouwt.

In het nummer van 8 Augustus verhaalt de kapitein aan Himare de geschiedenis van het vergaan van de Zeemeeuw. Het eiland Oro in dat verhaal is Aruba; Curaçao wordt aangewezen met Z. en de brik Z.M. is de Zeemeeuw. In hoofdzaken zijn de verhalen 1 (uit De Vrijmoedige) en 2 (uit de A migoe) hetzelfde, maar in bijzonderheden verschillen ze nog al.

Zoo lezen we in verhaal 2 , dat de oude zeerob zijn historie vertelde met tranen in de oogen, uit berouw over zijn medeplichtigheid; dat het Aruba-goud voor Nederland in vaten, met zout gevuld, verborgen was, en niet door de zeeroovers gevonden werd; 
dat de kapitein van de Zeemeeuw op het eerste stopschot gehoorzaamde; dat het verdere onderzoek van het schip niet door de kapitein zelf, zooals in verhaal 1, maar door twee manschappen gedaan werd. Volgens verhaal 2 werd eerst de Zeemeeuw lek gemaakt en daarna werd de zeilboot van de Zeemeeuw met 5 schoten in den grond geboord. Volgens verhaal 1 eerst met 4 schoten de zeilboot, daarna de Zeemeeuw.

Volgens verhaal 1 werd al het Arubagoud meegenomen; volgens verhaal 2 ging het mee de diepte in.

Volgens verhaal 1 werd de Zeemeeuw gepraaid op den 6en dag en bleef de Beluche 9 dagen daarna op zee rondzwalken en werd op de 7e dag Mevr. D. vermoord; volgens verhaal 2 zijn deze cijfers respectievelijk 5,10 en 9 . Verder wordt nog in verhaal 2 meegedeeld, dat de vroegere scheepsjongen later „op de Engelsche kolonies" de echtgenoot van Mevr. D. heeft ontmoet.

Een merkwaardigheid is nog, dat het verhaal van $\mathrm{D}$ e $\mathrm{V} \mathrm{r}$ ijm o e d ig e is van 4 Mei 1861, het verhaal in de Amigoe begint op dezelfde datum van het jaar 1878 .

Wie is de schrijver van deze beide verhalen?

Het is de heer Johan Hendrik Bennebroek Gravenhorst geb. op Curaçao 4 Oct. 1830 en aldaar overleden op 29 April 1919. Hij was gehuwd met Anna Gerbrecht Hellmund. Aanvankelijk zeeman en kaptein van een bark, waarmede hij geregeld reizen maakte van Curaçao naar Aruba, Goagira, Cuba enz., ging hij later wonen op zijn plantage Gasparito en werd districtsmeester. $Z$ ijn vader was Mr. Jacob Bennebroek Gravenhorst, gehuwd met Welmoet Nagel. Deze was president van de rechtbank op Curaçao en in die kwaliteit wnd. Gouverneur tijdens het verlof en na het ontslag van Jhr. Rammelman Elsevier, van 28 April 1854 tot 23 Febr. 1856, de komst van den nieuwen Gouverneur R. F. van Lansberge.

Het verhaal in Goagira (toen Gravenhorst dus 45 jaar was) is waarschijnlijk, maar dan met zeer veel fantasie, de geschiedenis van zijn wedervaren onder de Indianen van dat land.

Wat vertelt de historie van het vergaan van de Zeemeeuw?

Dit tijdvak van de Curaçaosche geschiedenis, 1816-1828, is beschreven door Mr. B. de Gaay Fortman in D e W e s t-I ndische Gids van het jaar 1927. Deze vermeldt ook het vergaan van de Zeemeeuw, waar hij melding maakt van de poging door gouverneur Cantz'laar aangewend, om in het moeder- 
land een afzetgebied te vinden voor het zout van deze eilanden Dit zout zou als lading kunnen gebruikt worden voor de schepen, die met bijna geen of zonder vracht naar het moederland moesten vertrekken. „Zoo werden”, schrijft hij op bladz. 246, „dan als eerste zending met de Zeemeeuw, kapitein J. R. Bonning, het schip waarmee Niewindt de reis gemaakt had, en dat reeds zes maanden op vracht had liggen wachten, 600 vaten „Bonairesch” zout aan de „consignatie” van de heeren Crommelin en Scheidius gezonden tegen betaling van veertig stuivers Ned. het vat voor vracht. Den 1sten Maart 1825 vertrok dit schip van Curaçao onder convooi van $\mathrm{Zr}$. Ms. brik Kemphaan tot de Mona-passage. Nimmer heeft men verder van dit schip iets vernomen, zoodat het vermoeden voor de hand ligt, dat het met man en muis vergaan of wellicht door zeeroovers genomen is".

In een noot weerlegt deze schrijver als onjuist de mededeeling van Teenstra, die als vertrekdatum 1 Mei opgeeft en dat het eerste goud van Aruba aan boord was.

Volgens het gouvernementsjournaal was het Aruba-goud, een hoeveelheid van 71 k.g. aan Van Raders meegegeven, toen deze met baron Krayenhoff op Zr. Ms. fregat van 44 stukken Amstel op 20 Augustus naar Nederland ging (zie Encycl. voor W. I. in v. Goud). Volgens De Gaay Fortman waren wel aan boord de weesmeester Mr. W. Webb Duyckinck en 14 militairen, wier diensttijd verstreken was.

Teenstra zegt wel, dat er enkele passagiers van Curaçao aan boord waren, maar noemt geen namen.

De Curaçaosche courant uit het jaar 1825 geeft geen ander bericht, als waarmede we dit artikel openden. Passagiers worden niet vermeld, noch lezen we van eenig verder bericht aangaande het verloren gaan van de Zeemeeuw.

Vooral dat de naam van Mr. W. Webb Duyckinck als passagier niet vermeld wordt, vinden we merkwaardig, daar we geregeld voorname passagiers vermeld vinden; maar nog merkwaardiger ia, dat we in de couranten van Dec. 1925 verschillende malen een mededeeling vinden opgenomen van de weesmeesteren G. Vos en $M r . W . W$. Duyckinck, omtrent een verkoop als gemachtigden van een zekere Theod Vaerst.

Omtrent de aanwezigheid van een Mevrouw D(uyckinck), waarvan Gravenhorst spreekt, tasten we dan ook geheel in het duister.

Al even duister is de persoon van den bisschop. Zelfs vermoeden 
we, dat hịer een verwarring heeft plaats gehad van den schrijver of zegsman (de oude zeeman), doordat de Zeemeeuw op de reis naar Curaçao, waar het schip op 27 Aug. 1824 was aangekomen, aan boord had Pastoor Niewindt, den lateren bisschop en Apostolisch vicaris van Curaçao.

Gravenhorst zegt in zijn verhaal, dat dit de twee eenige passagiers waren (Mevr. D. en de bisschop), terwijl De Gaay Fortman nog spreekt van 14 militairen. Was dit laatste het geval, dan zou vermoedelijk wel anders zijn opgetreden tegen de 13 zeeroovers, dan Gravenhorst beschrijft.

Zeeroverijen waren in de dagen van de Zeemeeuw geen denkbeeldige gevaren. Mr. De Gaay Fortman schrijft in zijn reeds aangehaalde studie (bladz. 100)) „In de loop van 1822 vond de „koopman Antony Mattey in de herhaalde geweldenarijen ter „zee aanleiding, den gouverneur te vragen om lettres de marque „,voor zijn schoeners Diana en Anna om die schepen tegen zee„roovers te verdedigen en tegelijk hindernis toe te brengen aan „de schandelijke bedriegerij, welke gepleegd werd door vaartui„gen, die zich niet ontzagen van de Nederlandsche vlag tot hun „privaat oogmerk valsch gebruik te maken. Cantz' laar weigerde „dit, omdat Nederland niet in oorlog was, wel werd Mattey toe„stemming verleend om zijn schepen tot eigen verdediging tegen "zeeroovers te wapenen".

En verder op bladz. 245: „De handel, die niet naar het Zuiden „ging, had meermalen last van zeeroovers. D e C u r a ç a o„s che c ourant van 19 Januari 1824 bracht het bericht „van de buitmaking van de golet Dorothea van George Curiel „onder de kust van Puerto Rico door een klein zeerooversvaar„,tuig onder de Fransche republikeinsche vlag, waarbij de geheele „bemanning op een jongen na vermoord werd.... Van toen af „,verleenden herhaaldelijk de Nederlandsche oorlogsschepen con„vooi aan koopvaardijschepen, die van Curaçao uitzeilden, tot „aan de Mona-passage.

We komen thans op de naam van den kaperkapitein, door Gravenhorst aangegeven enkel met de letters B. L.

We vermoeden, dat hiermede bedoeld zal zijn Bartholomeo Lion, ook wel Leon geschreven. Deze stierf in het jaar 1882; op welke leeftijd heb ik niet kunnen achterhalen, maar in hogen ouderdom; hij heeft de geschiedenis van de Zeemeeuw nog 62 jaren overleefd, als hij tenminste de kaperkapitein geweest is.

Hij was een Corsicaan (vergel. het franse woord Corsaire voo 
zeeroover) van afkomst en heette eigenlijk Lioni. Van Carupano kwam hij op Curaçao en was familie van de Corsicanen Mattei, Agostini, Bianchi, en Blasini, die zich hier omstreeks 1820 vestigden.

Zijn naam komt echter niet voor in de schepenlijsten van D e $\mathrm{Curac}$ a o s che courant uit die dagen.

Antony Mattei, die we boven genoemd vinden in het citaat uit De Gaay Fortman, alsmede in het verhaal van Gravenhorst, waar de werf van Sjoon N. M. ongetwijfeld die van Nanna Mattei is, was de eerste Corsicaan, die op Curaçao kwam, en Agostini, een stamvader van sommige Curaçaosche families, geboren op Corsica in 1802 , was aan hem verwant.

Of Mattei zich aan zeeroverij heeft schuldig gemaakt, valt niet uit te maken. Zeker blijkt uit bovenstaand citaat, dat zijn schoeners Diana en Anna tegen zeerovers door bewapening beveiligd waren.

Wijlen de historicus P. A. Euwens, aan wien ik talrijke aantekeningen in zake deze stof heb ontleend, stelt zich de vraag: Zou het misschien een dezer schepen (van Mattei) zijn geweest, die de Zeemeeuw heeft aangevallen?

Volgens De Curaça o s che courant van 1825 , is er in die dagen geen Beluche uitgevaren of binnengekomen; wel vinden we in een schepenlijst, dat op 2 Maart (1 dag na de Zeemeeuw) de Diana is uitgeklaard, gezagvoerder Dominguez, met bestemming La Guaira, en op 18 Maart werd deze golet weer ingeklaard als komende van Puerto Cabello.

Eenzelfde tijd is dus dit schip buitengaats geweest als het kaperschip in het verhaal van den ouden zeeman.

We geloven, dat in het verhaal van Gravenhorst deze grond van waarheid opgesloten ligt, dat de Zeemeeuw, volgens de verklaring van een ooggetuige (de vroegere scheepsjongen) in handen van Curaçaosche kapers gevallen is.

Omtrent de nadere bijzonderheden, wie deze Curaçaosche kaper was? wie de passagiers aan boord van de Zeemeeuw waren? tasten we echter nog in het duister.

Het is mogelijk, dat de Curaçaosche archivalia, welke niet onder ons bereik maar in patria zijn, meer klaarheid brengen kunnen omtrent dit drama in de Caraïbische zee.

NASCHRIFT. De heer Hulsman geeft mij in zijn begeleidenden brief vrijheid om in bovenstaand artikel te veranderen en te 
verbeteren, indien ik in de loop der jaren nadere gegevens gevonden heb. Inderdaad heb ik nog een vondst gedaan. Ik maak van deze gelegenheid gebruik, om drie punten in mijn artikel van negen jaar geleden, die pater Hulsman min of meer in twijfel trekt, met de stukken te staven.

1. Waren er wel 14 militairen aan boord van de Zeemeeuw? Hieromtrent kan geen twijfel bestaan. Het gouvernementsjournaal (Oud-archief van Curaçao enz. op het Rijksarchief, no. 242) vermeldt op 1 Maart 1825 letterlijk: „Het Nederlandsche koopvaardij schip de Zeemeeuw gevoerd door schipper J: R: Boning, aan boord hebbende de lading die vermeld staat op het hierbij, als bijlaag, gevoegde manifest La A:, is heden naar Amsterdam vertrokken, onder convooi van Z: M: brik Kemphaan tot door de mona passage; mede nemende veertien militaire manschappen van het garnizoen alhier, wier tijd van dienst geexpireerd is".

Er staat dus met zooveel woorden, dat het schip met deze lading en militairen is vertrokken.

2. Was toch niet het goud aan boord? Het gouvernementsjournaal vermeldt met zooveel woorden, dat het goud in Augustus 1825 aan baron Van Raders is meegegeven, toen deze met de Kemphaan naar Nederland ging. Tegen afdracht van dit goud mocht gouverneur-generaal Cantz'laar $f 26.698 .90$ op het departement van Koloniën trekken. D e $\mathrm{Cu}$ r a ç a o s c h e Cou$\mathrm{r}$ a n t van 11 Maart 1826 deelt mee, dat een stuk afgedragen is aan het museum te Leiden. Prof. C. G. C. Reinwardt heeft dit goud onderzocht en daarover geschreven in de $\mathrm{N}$ i e u w e verhandelingen der eerste klasse van het Koninklijk Nederlandsch Instituut van Wetenschappen, Letterkunde en Schoone Kun$\mathrm{sten}$ te A m s te r d a m. De volgende zending van Curaçao naar Nederland heeft volgens het gouvernementsjournaal in 1827 met het paketvaartuig Curaçao plaats gevonden. Deze overeenstemming met de West-Indische Encyclopaedie lijkt mij eveneens afdoend.

3. Was mr. W. Webb Duyckinck aan boord? Ik heb in mijn oude aanteekeningen niet meer kunnen vinden, waaraan ik deze mededeeling ontleend heb. Wel vind ik in het gouvernementsjournaal op 11 Jan. 1825, dat de gouverneur-generaal gunstig beschikt op ,een rekwest van Mr. W. W. Duyckink mede administreerende weesmeester en lid van het Collegie der wees- onbeheerde en desolate boedel-kamer alhier, inhoudende verzoek om zich ter genezing der kwaal waaraan hij laboreert, voor den tijd 
van een jaar naar Nederland te mogen begeven”, ,ingaande dat verlof met den dag van zijn vertrek uit deze kolonie". Afdoend is echter iets nieuws, dat ik vond. In het Oud-archief van Curaçao no. 1235 , de minuut-notulen der vergaderingen van het bestuur van de weeskamer vindt men onder dagteekening van 11 September 1826 een bericht aan den Raad van politie naar aanleiding van een verzoek van de nabestaanden van $\mathrm{mr}$. W. W. Duyckinck betreffende diens nalatenschap. In dat stuk is vervat een mededeeling van den anderen weesmeester Vos over zijn waarneming van mr. Duyckincks belangen ,met en zedert het vertrek naar het moederland van het Lid Mr. W. W. Duyckinck aan boord het Nederland (sic!) Schip de Zeemeeuw op primo Maart des voorgaande Jaars 1825". Maar, zal men zeggen, hoe kunnen dan nog in Dec. 1825 in De Curaça os ch e c ou rant mededeelingen voorkomen van weesmeesteren G. Vos en mr. W. W. Duyckinck als gemachtigden van Theod. Vaerst. Ook dit is te verklaren. Beide heeren waren nu eenmaal gemachtigd in hun hoedanigheid en bleven dat. Voorts was er met instemming van den gouverneur-generaal een schikking getroffen tusschen Duyckinck en Vos, inhoudende dat laatstgenoemde „,buiten nadeel van" eerstgenoemde zich ,alleen met de werkzaamheden van weesmeesteren zal belasten", en het is dan ook wel zeer eigenaardig, dat de notulen der vergaderingen van de weeskamer steeds vermelden, dat alle leden aanwezig zijn. Dat Duyckinck overleden was, werd eerst in den loop van 1826 aangenomen; zijn opvolger, 18 Juli 1826 benoemd, trad 1 Januari 1827 in functie. Het komt mij voor, dat de oude heer Gravenhorst, hoe spannend zijn verhaal ook is, maar wat gefantaseerd heeft; vandaar, dat hij in 1914 niet meer wist, hoe hij het in 1908 verteld had.
Amsterdam 10 Juni 1936.
B. DE GaAy Fortman. 